NB: This is an author's version of the paper published in Med Health Care and Philos (2014)

17:143-154. DOI 10.1007/s11019-013-9519-8. The final publication is available at Springer via http://link.springer.com/article/10.1007\%2Fs11019-013-9519-8 This version may differ slightly from the published version and has different pagination.

On deciding to have a lobotomy: either lobotomies were justified or decisions under risk should not always seek to Maximise Expected Utility.

\title{
Rachel Cooper
}

\section{Abstract}

In the 1940s and 1950s thousands of lobotomies were performed on people with mental disorders. These operations were known to be dangerous, but thought to offer great hope. Nowadays, the lobotomies of the 1940s and 1950s are widely condemned. The consensus is that the practitioners who employed them were, at best, misguided enthusiasts, or, at worst, evil. In this paper I employ standard decision theory to understand and assess shifts in the evaluation of lobotomy. Textbooks of medical decision making generally recommend that decisions under risk are made so as to maximise expected utility (MEU) I show that using this procedure suggests that the 1940s and 1950s practice of psychosurgery was justifiable. In making sense of this finding we have a choice: Either we can accept that psychosurgery was justified, in which case condemnation of the lobotomists is misplaced. Or, we can conclude that the use of formal decision procedures, such as MEU, is problematic.

Keywords Decision theory _ Lobotomy _ Psychosurgery _ Risk _ Uncertainty 


\section{Introduction}

In the 1940s and 1950s thousands of lobotomies - operations designed to destroy portions of the frontal lobes - were performed on mentally ill people. Nowadays, lobotomies are typically seen as belonging to a psychiatric dark-age (see, for example, Valenstein, 1986; Goldbeck-Wood, 1996; Day, 2008). The standard line has it that such therapies were unjustified, and that the practitioners who employed them were, at best, misguided enthusiasts, or, at worst, evil. Lobotomies have become unacceptable to the extent that campaigners have sought to have Egas Moniz, the Portuguese neurologist who invented the procedure, retrospectively stripped of his Nobel Prize (Sutherland, 2004). At the time that they were used, however, lobotomies were known to be dangerous, but were considered to offer great hope, and were often welcomed by practitioners, patients, and the public. Then, the risks seemed worth taking; today they do not. Given that people in the past were no less rational than we are today, this presents us with a puzzle. Were those who employed lobotomies wrong? Or is the current condemnation of such practices misguided? In this paper I employ standard decision theory to determine whether there is a point of view from which the use of lobotomies was justified.

Re-evaluating the justifiability of the past use of lobotomies is worthwhile for two main reasons. First, considering whether it might have been rational to elect to have a lobotomy can serve a case study for thinking through how we might make decisions with high stakes under conditions of risk. Decision making under such difficult circumstances is frequently required. Whenever a disorder causes great suffering, but the only effective treatments carry great risks, it is tough to decide whether the treatment is worth undertaking. Similar problems also arise outside of medicine, for example, decisions about energy policy and climate change are also high stakes decisions where the 
possible results of various courses of action are unclear. Lobotomy can serve as a helpful case study for thinking through the problems involved in such decision making as it provides a well studied historical example where the necessary facts are all available for assessment.

Second, the discrediting of lobotomy has cast a long shadow over the way in which psychiatry is practised. Disquiet about lobotomy led to "radical" somatic therapies, not only psychosurgery, but to a certain extent also E.C.T., being side-lined in favour of drug-based therapies - a situation which continues to this day (Johnson, 2009). Re-evaluation is now particularly worthwhile because psychoactive medications have not fulfilled their initial promise. When modern antidepressants and antipsychotics were first introduced in the 1950s they seemed to be wonder-cures. Over time, however, the long term side-effects and effectiveness of psychoactive medications have often proved disappointing. If it turns out to be the case that radical treatments, such as psychosurgery, might sometimes have been justified, this might lead to a re-evaluation of current treatment choices.

Some historical work has already begun the process of re-evaluating psychosurgery. In Great and Desperate Cures (1986), Elliot Valenstein makes it clear that lobotomy was a mainstream medical therapy, rather than the fringe practice of a few mavericks. In his account, lobotomy must be understood as one amongst other drastic biological treatments (insulin coma, metrazol shock, E.C.T.) all of which were resorted to in desperation by over-stretched mental hospitals. In the final analysis, however, Valenstein condemns the lobotomy programs as an example of "uncritical enthusiasm running rampant and causing great harm to desperate patients" (1986, p.xi). In his account, the tragedy of lobotomy is that the treatment passed into widespread use before being subject to adequate trials. Valenstein suggests that systems for subjecting surgical techniques to controlled trials (along the lines managed by the FDA in the approval of pharmaceuticals) must be developed to prevent such mistakes happening again. 
In Last Resort: Psychosurgery and the Limits of Medicine (1998) Jack Pressman argues for an account of clinical efficacy whereby whether a treatment "works" depends on the extent to which it addresses context bound needs. He thus claims that lobotomy "worked in 1949 (and not now)" (p.194). In 1949, psychosurgery was the "last resort" in an armoury of graded somatic treatments. A patient might start with psychotherapy, pass on to E.C.T. and insulin coma, until eventually, if these less radical therapies failed to produce results, lobotomy might be used in an attempt at human "salvage". As contemporary understandings of mental health tended to run together personal wellbeing and manageability, there was then no apparent tension between the needs of institutions and those of the patient. Thus lobotomy could be promoted as both humane and useful. With changes in the physical and social environment in which mental disorder occurs, most notably the discovery of chlorpromazine and rise of the civil rights movements, the therapeutic niche that lobotomy once usefully occupied has disappeared. Thus lobotomy would no longer "work" today.

Aimed at a more popular audience, Jack El-Hai's The Lobotomist (2005), a biography of Walter Freeman, a key advocate of psychosurgery, presents a broadly sympathetic picture of Freeman. In El-Hai's account, Freeman is motivated by ambition, and an excess of energy, but also by a genuine desire to relieve his patients' suffering.

This paper goes beyond these works. Here I will not only argue that lobotomy made a certain sort of sense within the context of the 1940s and 50s, I will argue that in that context, and with the best evidence then available, a decision maker employing the procedures recommended in textbooks of medical decision making in use today would recommend lobotomy in certain cases. The methodology of this paper is justified by its aims. I will use current decision theory to seek to determine whether a patient might rationally have decided to have a lobotomy. Prima facia this may 
seem anachronistic - surely no such patients would consciously employ formal decision procedures! However, many decision theorists think that the rules that they render explicit are implicit in the decisions that are made by normal people. In so far as patients and their families weighed up the available evidence, and made decisions as to whether lobotomy on balance seemed worthwhile, their decision making may well have been in accord with the procedures advocated by decision theorists. ${ }^{1}$ Furthermore, for my project, figuring out what would be made of 1940s and 50s data using today's decision procedures make sense. Although I employ a historical case study my ultimate aims are to raise questions about current decision theory, and to reconsider the shadow that lobotomy still casts over the practice of psychiatry today.

\section{Lobotomies - what were they and what did they do?}

Psychosurgery is the attempt to alter mental states and behaviour by damaging healthy brain tissue. Although there were earlier, more primitive, and later, more sophisticated, attempts at psychosurgery, ${ }^{2}$ here we will focus on the pre-frontal lobotomies that were performed on thousands of mentally ill patients in the 1940s and 50s.

Egas Moniz and Almeida Lima operated on the first series of twenty patients in 1935 (Moniz, 1936). Their initial technique was to destroy part of the frontal lobes by the injection of alcohol. However, the extent to which the liquid dispersed was hard to judge. Moniz's improved technique employed a special instrument, a leucotome, which was inserted into the frontal lobes (Moniz, 1937). When the leucotome was at the right depth a wire loop was released from the end of the instrument. As the leucotome was twisted a core was cut loose in the brain. The leucotome was inserted, at various angles, through burr holes on either side of the skull and a series of cores cut in the frontal lobes. The 
operation was "blind" (i.e. the surgeon could not see the brain tissue that was cut) and damage to blood vessels could result in secondary damage to unintended areas of the brain.

Of his first series of twenty, Moniz claimed that seven patients recovered, seven improved, and six were unaffected by the operation (Moniz, 1936). Following Moniz's report, other surgeons around the world began to experiment with lobotomy. The first operation in the U.S. was performed in 1936 by Walter Freeman and James Watts (Freeman \& Watts, 1937). Freeman and Watts became key players in the spread of lobotomy across the United States. Watts and Freeman themselves performed a great many operations, and they published a book, Psychosurgery (1950; with Hunt, 1942), which further popularised the procedure. Freeman was also responsible for developing the infamous transorbital technique (Freeman, 1949), in which brain material was cut using an ice picklike instrument inserted through the eye socket.

Many of those who performed early lobotomies considered the attempt to be partly justified by experiments on trained chimps performed by John Fulton at Yale (see, for example, Freeman \& Watts, 1937). The chimps had been trained to solve puzzles and one had developed an experimental neurosis - when she made mistakes in tests she would fly into a rage. After removal of the frontal lobes the chimp made more mistakes on tests but no longer became upset by them. Early lobotomists also cited experience with tumours and brain injuries in their support; many case studies showed that people with damaged frontal lobes could often function surprisingly well (see, for example, Freeman \& Watts, 1937; Fleming, 1944).

At the theoretical level, justification for cutting sections of the frontal lobes was shaky. Moniz claimed that psychotic thoughts are caused by neuronal circuitry becoming fixed (Moniz, 1936). On his account, a lobotomy cut away the fixed pathways allowing the brain to regenerate healthy 
flexible ones. However, the fact that Moniz combined a theory involving regeneration with reports of recoveries merely one week after the procedure suggests that his theory may have been a decorative afterthought. In any case, other practitioners had other theories. Freeman believed that lobotomy left the underlying psychosis untouched but removed the "emotional sting" (Freeman and Watts, 1950, p.xiii). On his account, the patient who hallucinated pre-lobotomy would still hallucinate postlobotomy, but no longer become distressed.

The results of the operations were mixed. Some patients died on the operating table; some committed suicide post-operation. Others were left severely brain damaged and were reduced to a state where they were largely unaware of their surroundings. On the other hand, on occasion the operation proved stunningly successful. In his book, The Last Resort (1998), Jack Pressman discusses the case of Rose Thorner who received a lobotomy in 1947 (pp.264-270). Rose had been diagnosed as suffering from involutional melancholia. She had spent ten years on a locked ward where she spent her time asking to be allowed to die, smearing faeces, and assaulting patients and staff. Postlobotomy she was discharged to a lodging house, where she maintained a busy social life and did voluntary work at a local hospital. Friends considered her recovered and acquaintances found her " $100 \%$ normal".

The outcomes of other cases were more ambiguous. Post-lobotomy, patients might no longer be troubled, but still seemed to have lost something. Many had to remain in hospital but became more "manageable". In the words of the physicians at Delaware State Hospital, ...many of these miserable, unhappy, restless individuals who paced the floor wringing their hands, moaning, groaning, sometimes yelling and screaming... were transformed into quiet, 
placid, uncomplaining persons who showed little concern about their troubles. (Pressman, 1998, p.207)

To modern ears, the extent to which such a transformation is for the better is not entirely clear. Other patients managed to return home post-lobotomy but their personality was altered by the operation. Sometimes changes were minimal. Freeman considered that moderately successful lobotomies had produced,

a large number of patients [who] are living an ordinary undistinguished life, slightly flattened emotionally, a little slow, a little careless, but continuing with their usual activities (Freeman, 1953, p.272).

More serious character changes also occurred. One patient reported that as a result of the operation, "In my heart I've no pity or feeling, and I used to have". Relatives of other patients reported that, "She's shallower than she was", and "He's quite a tolerable and pleasant old man now, but he's simple" (Partridge, 1950, p.45 and p.47).

By the early 1940s relatively large-scale outcome studies were available. A 1943 review of 618 lobotomies found that 215 patients had "recovered" and 194 were "much improved" (Ziegler, 1943). 12 patients had died as a direct result of the operation, 2 had committed suicide, and 8 were worse. Looking at place of residence, 277 patients remained in hospital, 60 were at home but unable to work, and 251 were at home and working full or part-time.

Later studies fairly consistently reported that $1 / 3$ of patients greatly improved post-operation, $1 / 3$ somewhat improved, and 1/3 remained the same or became worse. Death rates were around 3\% 
(Fleming, 1944; Board of Control England and Wales, 1947; Oltman et al, 1949; Friedman et al., 1951; Greenblatt and Soloman 1953). About 6\% of patients experienced seizures after operation, and a few became incontinent, although incontinence typically cleared-up after a few weeks (Fleming, 1944).

Judged against today's standards, many of these early studies are methodologically quite poor. Controlled studies had not yet become the norm in medicine; ${ }^{3}$ groups of patients were simply subjected to treatment and the results reported. Typically results were assessed by the same practitioners who had performed the treatment. Measures of outcome were subjective; often studies merely included tables with numbers "improved", "unimproved" and "worse", and included some illustrative case studies.

Against this background, results from an early controlled trial by Friedman et al. (1951) are worth reporting in some details. Friedman et al. studied 254 patients who had lobotomies and compared their outcomes with 100 controls. The controls were patients selected by medical staff as being suitable for lobotomy, but whose relatives refused permission for the operation. Of the lobotomised patients, eight died as a result of the operation and $12.3 \%$ experienced seizures post-operation. Two years after the operations, the outcomes of the lobotomised patients and controls were assessed. Of the lobotomised patients, $9.4 \%$ were symptom free, $73.2 \%$ were improved to some extent, $13.4 \%$ were unimproved or worse, and 3.9\% were dead. Of the controls, none were symptom free, $6 \%$ had improved to some extent, $92 \%$ were unimproved or worse, and $2 \%$ were dead. The study also reported the place of residence of the patients. $38 \%$ of the lobotomised patients and $2 \%$ of the controls were living at home. The rest remained in hospital. $60 \%$ of the controls and $6.6 \%$ of the lobotomised patients were in "disturbed wards" at the assessment date. 
Faced with results like these, not only physicians but also patients and their families often considered the risks of lobotomy worth taking. Here, in considering whether it might be rational to have a lobotomy, I shall focus on the decision that faced psychiatric patients in the U.S. in the late 1940s and early 50s. A great many operations were performed in the U.S., and most of available literature concerns U.S. patients. Conditions within U.S. hospitals varied greatly. In Asylum (1935) William Seabrook, who was an alcoholic, describes his stay in a hospital that he does not name, but that may have been Bloomingdale Asylum for the Insane in New York, a well-respected private institution. ${ }^{4}$ Seabrook had quite a pleasant time in the asylum. He spent the mornings engaged in crafts and the afternoons playing games. He received three-course meals, and had access to well-stocked libraries. However, conditions in other hospitals, particularly State Mental Hospitals, were often poor. In his 1946 exposé in Life Albert Maisel described many mental hospitals as being "little more than concentration camps on the Belsen pattern" (p.102). The accompanying photos show naked patients huddled in otherwise empty rooms. The text described beatings by attendants, and patients being left for long periods in restraints. Albert Deutsch's (1948) The Shame of the States contained similar material.

After a few years in a mental hospital, the odds of a patient leaving alive were slim. Based on their study of patients in Ontario State Hospitals, Penrose and Marr (1943) estimated that once a patient had been in hospital for 4 1/2 years they had a $95 \%$ chance of still being in the hospital five years later. Finding similar results, Rupp and Fletcher (1940) studied people with schizophrenia and found that after five years of hospitalization only $4.2 \%$ ever improved. 


\section{Preliminaries}

In the next section I will look to decision theory to see how we should make decisions in conditions of risk. I will then go on to apply decision theory to the case of lobotomy with the aim of seeing whether it was ever be rational to choose a lobotomy. However before we can use decision theory to determine whether deciding to have a lobotomy could be a rational choice, there are several difficulties that need to be considered.

\subsection{Whose interests should we consider?}

Frequently mental disorder causes problems not only for the patient, but also for their families, the wider community, and the state. All may hope to benefit from a "successful" therapy, but assessments of the worth of particular outcomes may differ. Lobotomy brings out this problem particularly sharply. Rendering patients more "manageable" is an ambiguous outcome; it clearly serves the interests of hospital staff but it is not always clear that it in the interests of the patients themselves. Here, I will only consider the patient's own interests. This simplification is justifiable here. In what follows I shall argue that choosing to have a lobotomy may have been rational even when the only interests considered are the patient's. Arguing for this is more difficult than if all interests were considered. As such considering only the patient's interests will not alter the outcome of the argument.

\subsection{Who makes the decision?}

People suffering from severe mental disorder may not be capable of making rational treatment decisions. Some patients may be incapable of understanding their situation or the risks attached to 
treatment. At the extreme, patients may be mute and unable to make sense of what is said to them. Other patients may not be so impaired, but still lack insight into their condition. For example, someone who believes they have been chosen by God as his prophet may feel privileged, and judge that they have a good life. From the outside, however, if we assume that they are deluded, then they are pitiable. Patients who lack insight cannot judge the quality of their life and so cannot make rational decisions.

Other patients may be cognitively competent but still be incapable of making rational decisions because they are not motivated to pursue their own best interests. Consider the effects of depression on decision making. Studies have found that depressed patients are cognitively competent to make decisions (Appelbaum et al., 1999). Still there may be motivational problems; when told that electroconvulsive therapy carries with it a one in 3000 chance of death a depressed patient replied, "I hope I am the one" (Elliott, 1999, p.91). Not all patients will pursue their own interests because some hate themselves, and others simply have no interest in their own well being.

When working out whether it can ever be rational to choose a lobotomy we will consider what decision psychiatric patients should have made if they were rational (i.e. if they used the procedures recommended by decision theory, and were familiar with the best scientific evidence available at the time). This is an idealisation, but not always that much of an idealisation. Some mental disorders are episodic and thus some people are able to rationally choose treatments for their severely disordered future-selves. For simplicity, I here assume that in cases where it would be rational for a patient to elect to have a lobotomy, it would also be justifiable for a doctor to perform that lobotomy (this might be queried, for example, on the basis that while agents might be justified in imposing risks on themselves, doctors have special obligations to "do no harm"). 


\subsection{How should we rank the utility of the various possible outcomes?}

When trying to weight the undesirability of the possible outcomes of treatment or non-treatment we run into problems. Let's suppose that the patient we are considering suffers from severe mental illness on the back wards of a U.S. State Mental Hospital. How does their state compare with being severely brain-damaged, or being dead? At root our judgement depends on basic intuitions. Our valuations will depend on how much we value life and how much we value contentment as compared to intelligence.

The case of those patients who post-lobotomy were left severely brain-damaged but contented clearly brings out that the good life is not identical to the contented life. If fed and warm those with little mental capacity may yet be contented. But few would consider such a life to be a good life. Most of us do not just want to be contented but also to achieve various goals that we consider to be worthwhile - we want to maintain friendships, or pursue careers, or raise our children well, for example - and indeed many people choose to sacrifice much contentment in the pursuit of such goals.

The life of the severely brain-damaged but contented patient is not a good life, but is it better than the life of an unhappy and severely mentally ill person, say someone who suffers from severe depression? Famously, John Stuart Mill claimed that, "It is better to be a human being dissatisfied than a pig satisfied; better to be Socrates dissatisfied than a fool satisfied" (Mill, 1991, p.140) Following Mill, a long tradition has it that it is better to be intelligent but unhappy than unintelligent but contented. However, in the sentences prior to the oft-quoted claim from Mill, there is a less frequently quoted proviso. Mill only thinks that the life of a miserable Socrates is to be preferred to that of the fool's if it is at all bearable. I suggest that the life of someone with severe depression on 
the back wards of a 1940s or 50s U.S. hospital was not a bearable life, and that such a person was worse off than a contented and brain-damaged patient. Ordinarily, intelligence might be preferred to contentment because intelligence ordinarily enables us to achieve goals that we consider to be worthwhile. However, a patient in the 1940 s or 50 s was not in a position to achieve many worthwhile goals. As such, both the depressed patient and the brain-damaged patient come out about equal in terms of achievements. In addition, the depressed patient is also subjectively unhappy. As subjective happiness must be at least part of what goes up to make the good life, the depressed patient's depression means that their life is less good than that of the brain-damaged patient.

How, finally, does being severely brain-damaged, or being deeply depressed, compare with being dead? For my part, I think I would rather be dead than be a long term depressed patient in a 1940s or 50s U.S. State Mental Hospital, and rather be a contented and brain-damaged than either, but these rankings will of course be highly contentious. The most we can say with certainty is that none of these three possible outcomes has much going for it.

\section{Decision theory}

In this section we will leave lobotomies to one side and think about how we make decisions in more mundane situations. As this paper is aimed at readers not all of whom will be familiar with formal decision theory, the discussion here will start with the basics. It is important to distinguish between decisions that are made under risk and those that are made under uncertainty. Decisions are said to be made under risk when the probabilities of the various possible outcomes of an action are known. Decisions are said to be made under uncertainty when the probabilities of the various possible outcomes of an action are unknown. How the rational agent should seek to make decisions under risk and uncertainty is currently the subject of some debate. Here we will not be able to review all the 
approaches that have been proposed but will just examine some of the most prominent suggested procedures. The procedures discussed here will be sufficient both to make the case that decision theory suggests that for a 1940s or 50s patient to choose to have a lobotomy was arguably a rational choice, and also, as many of the potential problems that arise with the use of decision procedures are common to many different procedures, to illustrate these broader issues.

\subsection{Decisions under risk and Maximising Expected Utility}

When the probabilities of the possible outcomes of a course of action are known, it is often suggested that the rational agent should make decisions so as to Maximise Expected Utility (M.E.U.). ${ }^{5}$ That is they should take the option which could be expected to give the highest overall yield if repeated over time. To calculate the Expected Utility of each option one needs to multiply the value of each possible outcome by the probability of its occurrence and then add them together. Let's take a simple case as illustration: a raffle with 200 tickets, each being sold for $£ 1$, and a sole prize of $£ 100$. Suppose further that the agent values money in proportion to its amount i.e. they value $£ 100$ one hundred times more than $£ 1$ (this condition will not always be met, if I have modest desires and the only thing I want in life is a $£ 1$ bag of sweets then for me the utility of $£ 1$ will be more than $1 / 100^{\text {th }}$ the utility of $£ 100$ ), then in the above case, the expected utility of the various options is as follows: 


\begin{tabular}{|l|l|l|l|}
\cline { 2 - 4 } \multicolumn{1}{c|}{} & Possible outcomes & Calculating the & Expected Utility \\
\hline Buy a ticket & $1 / 200$ chance $£ 99(£ 100$ & $(0.005 \times 99)+(0.995 \times$ & $-50 \mathrm{p}$ \\
minus ticket cost $),$ & $-1)$ & \\
\hline Do not buy a & Certainty of no cost or & 0 & 0 \\
ticket & benefit & & \\
\hline
\end{tabular}

Table 1. Using Maximise Expected Utility.

If I follow the decision rule that I should Maximise Expected Utility then I should not buy a ticket. I can also use M.E.U. in situations where the outcomes are non-monetary. In such situations I just need to assign "utility units" to the various possible outcomes to reflect the extent to which I value them. Many writers suggest that M.E.U. can be used as a decision rule for making decisions regarding medical treatments and many textbooks endorse this approach (for example, Sox et al., 1988; Hunink et al., 2001; Rao, 2007; Schwartz \& Bergus, 2008).

M.E.U. can be used when we know the probabilities of the possible outcomes of a decision. It can also be used where we are not absolutely sure of the probabilities but know that they fall within some range. To do this one applies M.E.U. once for the optimistic case and once for the pessimistic case. It may be that M.E.U. recommends the same decision in either case - in which case, that is the decision I should make. Or it may be that M.E.U. recommends one course of action for the optimistic case and another for the pessimistic case - if this happens I will not know how to act. In a further variant, some suggest that in situations where the probabilities of various outcomes are unknown, but one is 
willing to make a guess, one can employ subjective probabilities (as originally suggested by Savage, 1954, endorsed by others, for example, Halter and Dean, 1971, p.93).

In seeking to justify M.E.U., theorists will often point out that if used as a decision procedure over a long series of events it can be expected to maximise expected outcomes. Thus using M.E.U. is a good idea - at least in cases where one is engaged in decisions which can be seen as part of a long series. How M.E.U. can be justified in the case of a decision maker who is making a one-off decision is more problematic (Luce and Raiffa, 1967, pp.20-21; Cohen, 1996). Suppose I'm trying to decide whether to have a lobotomy. Considering what would maximise my utility if I were to have a long series of lobotomies would be odd as probably I'll only be having one. ${ }^{6}$ What's more, in the lobotomy case, possible outcomes vary in value massively. I could end up either effectively cured, or dead; I'm highly unlikely to experience the "average" utility associated with the operation. ${ }^{7}$ At this point opinions split. Some think that M.E.U. can still be justified. I have to think of myself as one case in a long series of cases (where the series might be actual or hypothetical). I then have to think of the expected utility in my case as being a fraction of that expected in the long series. Others think that in the case of a one-shot decision where some but not all options entails a risk of potentially disastrous consequences the rational agent might choose not to M.E.U., but instead play safe and use a more cautious approach (for example, maximin). However, the decision whether to undergo lobotomy as made by someone who has suffered from long-term and severe mental disorder does not fall into this category. This is because whether one decides to undergo lobotomy or not there is a high chance that the outcome will be dismal. Whichever option is taken the potential for disastrous consequences cannot be avoided. 


\subsection{Regret Theory - and why it can't be used in this case}

The literature on medical decision making has recently included some discussion of regret theory, which might be used to provide alternative approaches to M.E.U. Regret theory suggests that when making decisions one might anticipate the regret (and possibly also the joy) one will feel if one turns out to have made the wrong (or right) decision and take this into account when forming one's decisions (eg Loomes and Sugden, 1982; Bell, 1982) ${ }^{8}$. Such approaches have recently attracted a good deal of attention in the literature on medical decision making as empirical studies suggest that many medical decisions are made in accordance with regret theory. When considering whether to undergo medical testing, many are motivated to take tests because they think about how sorry they would be if it turned out that they had the disease, but had turned down the opportunity to be tested for it (Tymstra, 1989). Similarly, when faced with having to decide whether to pursue aggressive, but marginally more effective treatment for cancer, many patients choose aggressive treatment because they anticipate the regret they would feel if they choose the less effective treatment and then experienced relapse (Smith, 1996).

Regret theory arguably provides a descriptive as opposed to prescriptive account of decision making. In any case, such approaches cannot be appropriately used by a patient who is considering whether to have a lobotomy. This is because if a lobotomy goes very badly one is not left in a state where one is capable of having regrets, and thus in the worse-case scenario there are no regrets to be anticipated. Here it is worth noting the asymmetry between the first and third-person viewpoint in making such decisions; in the case of an unsuccessful lobotomy the patient will not have any regrets, but a thirdperson may have. This raises interesting questions for medical decision making that employs procedures that take account of anticipated regrets and employ a proxy decision maker (i.e. when 
someone else is asked to make the decision for an incapacitated person on their behalf) that cannot be further explored in this paper.

\section{Was it ever rational to have a lobotomy?}

\section{$\underline{5.1 \text { The decision in the late } 1940 \text { s or early } 1950 \mathrm{~s}}$}

I will consider whether the use of lobotomy could be judged rational from the viewpoint of a patient in the late 1940s or early 1950s. This is the easiest case to consider, as at this time the probabilities of the possible outcomes of lobotomies appeared to be known. It is also the most important case, as most lobotomies were performed during this period.

By the late 1940s enough lobotomies had been performed for the risks associated with the operations to seem fairly well known. A patient in the late 1940s or early 1950s who was considering having a lobotomy thus seemed to face a decision under risk.

If offered the chance to be lobotomised, what choice should a patient have made? Let's suppose one suffered from a severe mental disorder, in the U.S., and had been in hospital for several years. Under these conditions, if one choose not to have a lobotomy, then data from the studies discussed in section 2, suggested that two years later one had around a 95\% chance of still being in the mental hospital, and a 5\% chance of having improved sufficiently to be released. On the other hand, if one had a lobotomy, one had about a 3\% chance of dying as a direct result of the operation, and about a $33 \%$ chance of having substantially improved, to the extent that one could have left the hospital. I suggest that being in the hospital or being dead are roughly equally bad, and as such I will award each of these possible outcomes zero utility points. Those who left hospital post-lobotomy could 
expect some personality damage as compared to those who left following a spontaneous remission. In addition, post-lobotomy about $6 \%$ of patients experienced seizures. Taking these potential problems into account, for our calculations, let's suppose that post-lobotomy "recoveries" are on average only $60 \%$ as good as spontaneous recoveries.

We are now in a position to use M.E.U. to decide whether to have a lobotomy:

\begin{tabular}{|l|l|l|}
\cline { 3 - 3 } \multicolumn{2}{l|}{} & Expected utility \\
\hline Lobotomy & $(0.33 \times 60)+(0.67 \times 0)$ & 20 \\
\hline No lobotomy & $(0.05 \times 100)+(0.95 \times 0)$ & 5 \\
\hline
\end{tabular}

Table 2: Using Maximise Expected Utility to evaluate the decision to have a lobotomy.

Using M.E.U., in such a situation we should clearly choose to have a lobotomy. It is worth noting that this result will be robust in the face of most possible challenges to the assumptions I have made. For example, I have suggested that a post-lobotomy recovery is only $60 \%$ as good as a spontaneous recovery. Obviously this estimate might be challenged, but so long as one thinks that a postlobotomy recovery is more than $15 \%$ as good as a spontaneous recovery, then M.E.U. still recommends lobotomy. ${ }^{9}$ Similarly, the result will remain robust in the face of reasonable revisions to the calculation by those who think that life in a mental hospital is of some value.

Thus, if we employ M.E.U., this suggests that a chronically ill psychiatric patient who chose to have a lobotomy in the late 1940s or early 1950s made a reasonable decision. At this point it is worth flagging up that one may have concerns about this result. Using M.E.U. the decision to have a 
lobotomy looks to have been clear-cut, but clearly, while such decisions may have been defensible, they were in some way problematic. This creates a dilemma. Either we accept that employing M.E.U. is a reasonable way to make decisions, and conclude that the decision to have a lobotomy was justified. Alternatively, in so far as we continue to find decisions to have a lobotomy problematic, we must find some problem with M.E.U. Possible problems with M.E.U., and with the application of formal decision procedures more generally, will be considered in Section 6 .

\section{$\underline{5.2 \text { The retrospective judgment }}$}

Up until the early 1950s the available evidence suggested that if one was a long-term psychiatric patient then having a lobotomy would greatly increase one's chances of leaving the hospital. As previously employed in the calculations in section 5.1, the accepted figures suggested that at least one third of lobotomised patients could expect to benefit greatly. Soon however the evidence supporting these figures would unravel; starting in the late 50s, a number of controlled studies with long follow-up periods reported results far worse than those previously found in the literature.

Barahal (1958) reported results from a 5 to 10 year follow-up study on 1000 patients. In his study only $16 \%$ of patients improved to the extent that they could leave hospital (with a further $5 \%$ lost to contact giving a possible total figure out of hospital of 21\%). A control group was made up of patients who were selected as suitable for operation but where consent for operation could not be obtained. In this group only $2 \%$ were discharged from the hospital after five to ten years. Barahal's results were worse than those reported in earlier studies, but he still considered them sufficiently good to justify psychosurgery is cases that proved unresponsive to other forms of treatment. 
However, in the same year, Robin (1958) reported on 198 patients who had leucotomies (as lobotomies were known in the U.K.) who were compared with 198 matched controls. Both groups were followed for ten years. Robin's found that "Leucotomy did not appear to (a) improve the chances of discharge from hospital; (b) accelerate discharge; (c) reduce the chances of readmission; (d) delay readmission; (e) reduce the number of readmissions; (f) reduce the total period of readmission; (g) improve hospital behaviour as judged by ward level” (pp.268-9). In short, in Robin's study, lobotomy did no good. Notably, the vast majority of Robin's patients had been hospitalised for less than two years prior to the operation. Spontaneous recoveries are most common in this period and so this may in part explain why the outcomes for Robin's control group were comparatively good.

In another influential controlled study, cited in editorials sceptical of the worth of psychosurgery in both the British Medical Journal (1965) and the Canadian Medical Association Journal (1964), McKenzie and Kaczanowski (1964) compared 183 patients operated between 1955 and 1957 with a control group. Most of McKenzie and Kaczanowski's patients had been ill for many years, but, again, they found "No significant differences in rate of hospital discharge." (p.1193).

Why did these later controlled trials find results so much worse than Friedman et al. (1951)? McKenzie and Kaczanowski (1964) conjecture that the explanation may have been that the control group used by Friedman et al. (1951) was made up of candidates for lobotomy whose relatives had refused consent for the operation. They consider such control groups to be inadequate as "there is a risk in assuming these patients to be comparable except for the operation itself: bestowal or withholding of consent for operation may reflect an underlying difference in family attitude with also could alter outcome" (p.1194). Here the thought seems to be that family support is important for recovery and that relatives who consent to psychosurgery are likely to be more supportive of the 
patient and thus increase the chances of recovery. Today the idea that consenting to psychosurgery would be correlated with support seems odd, and the putative explanation unsatisfying.

Whatever the explanation for the new and less favourable results, the important point for us is that the agreement that psychosurgery yielded good results broke down. Reconstructing a consensus proved impossible. The practical difficulties in designing adequately controlled studies became more and more apparent, rendering each study open to endless critique. Double-blind controlled trials had come to be the accepted gold standard for evaluating medications, but blinding for lobotomy is much harder than blinding for medication. A few studies employed sham operations, ${ }^{10}$ but many found these ethically unjustifiable. Furthermore it was unclear which factors were appropriately judged part of the treatment and which should be controlled. Lobotomists generally thought that the operation could only produce recoveries if appropriate after-care was given (for example, Fleming, 1944; Curran \& Partridge, 1963). The idea was that lobotomy created conditions under which a patient would become accessible to social and educational measures, which still had to be provided. However, ensuring that a control group received exactly the same support was very difficult; factors such as the attitude of the family were judged crucial, but obviously families would treat operated patients differently from unoperated controls. Problems with the methodology of trials were never adequately resolved, and later reviews reached no conclusion as to the worth of psychosurgery (Robin and Macdonald, 1975; Valenstein, 1976; O'Callaghan and Carroll, 1982). In any case, by the early 1960s interest in psychosurgery had dwindled, as the new psychoactive drugs had rendered psychosurgery largely obsolete. ${ }^{11}$ 


\section{Lessons}

Standard decision theory suggests that if one was a long-term psychiatric patient in the late 1940s or early 1950s in the U.S. it would be rational to choose to undergo a lobotomy. Note that this conclusion is far from supplying a justification for all the lobotomies that were in fact performed. Many operations were performed on patients who had not been ill for very long, or who were not very severely impaired. ${ }^{12}$ Still, even the limited defence of lobotomy suggested here may seem problematic, and in evaluating this finding we are faced with a choice. Either, we accept that deciding to have a lobotomy was rational. Or, if we hesitate to accept this conclusion we must find some problem with the decision procedures I employed in section 5. In this final section I will not come down firmly on one side or the other. In section 4.1 I have already discussed why one might doubt that M.E.U. should be used for one-off decisions, to finish I will outline three other potential worries about the use of formal decision procedures.

\subsection{First Worry: The assumption of fixed options for action}

Procedures such as M.E.U. assume that the range of possible courses of action is known and unchanging. Thus, in our example, the only options are to have a lobotomy or nothing. This may realistically reflect the options of a patient up until the early 1950s, as lobotomy would generally only be offered once alternative treatments, such as psychotherapy and E.C.T., had been tried and had failed. However, the range of possible treatments was soon to expand. Chlorpromazine became available in 1954 and overnight rendered lobotomy all but obsolete. The authors of one of the first articles on chlorpromazine note of one patient who improved greatly with the new drug, "A 
lobotomy had been proposed but was rejected by her family who had more faith than we did". ${ }^{13}$ Perhaps those who are severely ill should avoid radical therapies in the hope that a better effective therapy will soon be discovered?

It is not possible to include a precise factor for the possibility that a new treatment might be discovered when deciding whether to undergo a radical medical treatment. Discoveries are by their nature unpredictable (a discovery that can accurately be predicted has already been made). The best one could do, I guess, is to look back at some period of history, work out how many new treatments became available in that time, and work out the probability that a new treatment will become available within some fixed time period based on that.

However, while estimating the odds of a better novel treatment being developed is problematic, the fact that a better treatment may be developed should make a difference to decision making. Given that new and more effective treatments may be discovered in the future there is something to be said for keeping one's options of pursuing future treatments open. Some current choices may be reversible, in the sense that if a better treatment comes along one will be able to switch to the new treatment; other current choices are irreversible. In so far as it involves causing permanent brain damage lobotomy is an irreversible procedure. If a new treatment comes along once one has decided to have a lobotomy one will no longer be as able to benefit from it as one would have in one's prelobotomy state. In contrast, decisions to take psychoactive drugs, or to have no treatment, are comparatively reversible (such decisions may not be entirely reversible as long term drug treatment and also prolonged untreated depression may themselves result in neurological damage). ${ }^{14}$

The extent to which someone should pause before agreeing to an irreversible intervention will depend on their situation. Given their limited life expectancy, the elderly have a lower chance of 
living long enough to see a better treatment developed, and might accept an irreversible treatment that would be unwise in the case of a younger person. The urgency and awfulness of the patient's current situation also matters. The situation of some patients may be so dire that waiting for a better treatment to be developed may not be an option; those who are actively suicidal may not be able to wait. While the irreversibility of lobotomy means that it might have been an unwise choice in some cases (in particular for those who were young and not desperately ill), in other cases (for example for those who were elderly and suicidal) even irreversible treatments would have been justified.

\subsection{Second worry: Quantifying the probabilities of outcomes}

The lobotomy case study also serves to illustrate the difficulty of quantifying the probabilities of the various outcomes of a course of action. Even when we think that we know the probabilities, we may not. The lobotomy case study illustrates well how scientific "evidence" can unravel, such that even the best supported estimates of the probabilities of the outcomes of courses of action can later come to seem doubtful. In the late 1940 s it was thought to be a known fact that about 1/3 of lobotomised patients recover, and that in the absence of treatment these patients had little chance of recovery. Later these figures came to be contestable. The history of psychiatry includes other examples of cases where treatments are "known" to be efficacious at one time, but then later this judgment has to be revised. Insulin coma therapy in schizophrenia (Jones, 2000) may be the best known example. "New generation" antidepressants in mild depression may go the same way (Kirsch et al., 2008). Revisions in estimations of the efficacy of treatments can occur both as the methodology of trials becomes more sophisticated, and also as past frauds and biases are brought to light. A version of the pessimistic induction suggests that our current best "knowledge" may similarly come undone. 
In Great and desperate cures (1986) Elliot Valenstein is more optimistic about the ability of carefully controlled trials to supply reliable data about the outcomes of treatment. He thinks that the problem with the lobotomy programs was that the new treatment was put into widespread use before it had been adequately tested. He proposes that a system for controlled tests for new surgical techniques should be implemented (on the model of the FDA system for approving new drugs), and implies that this might enable problems with future treatments to be avoided. I am less optimistic than Valenstein. It should be remembered that a controlled study of lobotomy was available comparatively early (Friedman et al., 1951). The problem was that later studies found different results. While one might claim that the methodology of later studies was somehow better, arguments about trial methodology never end. Thus I think it must remain a real concern that the findings of any particular studies may come to be thought doubtful in the future because of refinements to methodology. In addition, as recent studies of bias in drug trials make clear (Angell, 2005), fraud and bias are ever present concerns.

\subsection{Third Worry: Quantifying the desirability of outcomes}

Formal decision procedures require one to quantify the desirability of the various outcomes. But, arguably, there is something fishy about deciding that being severely depressed and having convulsions is, say, $30 \%$ worse than just being depressed, and maybe $70 \%$ worse than being severely brain-damaged but contented. I might try turning to various studies for guidance, but all have limitations. Figures drawn from surveys of "willingness to pay" are just figures drawn from the guesses of many people. I might try relying on the judgments of past patients who have experienced

the intervention. ${ }^{15}$ Still, in this case, asking those who have had lobotomies how it was for them will be of limited use; those whose lobotomies go badly are left unable to make complaints. Even when 
past patients can provide me with data about their experience, I still have to judge the extent to which I think I would experience the possible outcome similarly; even if, say, 20\% of those who experience a lack of motivation post-lobotomy find this tolerable, this doesn't mean that I would find it tolerable. At the end of the day, the figures that are used in quantify the desirability of various outcomes will likely be only weakly justifiable. Still, once the figures have been selected, and multiplied and added together, the risk is that they take on a life of their own. The worry is that the use of numbers helps create the illusion of objectivity where there is none. This can promote a kind of hubris; really one has no idea how to act, but performing calculations with made up figures encourages one to forget one's ignorance.

These limitations of decision theory are sources of concern. However, while it is comparatively easy to point out the limitations with formal decision procedures, coming up with a positive account of how decisions might better be made is harder. The best I can do is to suggest that in addition to employing formal decision procedures, thought should be given to matters such as whether a course of action is irreversible or not, and to whether there is much chance of new and better ways of doing things being discovered in the future. Furthermore, it must be remembered that "best evidence" regularly comes to be overturned at a later date, and that the utilities of various outcomes are always subjective and revisable. Even with such points in mind, however, if I had been a U.S. psychiatric patient in the 1940s it would have been rational for me to elect to have a lobotomy, in so far as M.E.U. would have recommended this action and it is not clear how decisions might better be made. This being said, later studies would suggest that such a decision would turn out to have been the wrong decision. The final lesson to be drawn from the case of lobotomy is that decision making is fallible. Anyone can make a mistake, and if our own decisions turn out to be correct, this will be down to luck as well as wisdom. An awareness of this fallibility should lead us to an appropriate 
modesty in our own decision making, and should mute our condemnation of others when retrospectively it seems that wrong decisions have been made.

\section{References}

Appelbaum P., Grisso T., Frank E., O'Donnell S. \& Kupfer, D. 1999. Competence of depressed patients for consent to research. American Journal of Psychiatry ${ }_{2}$ 156,1380-4.

Angell, M. 2005. The truth about the drug companies. New York: Random House.

Barahal, H. 1958. 1,000 prefrontal lobotomies: a five to 10 year follow-up study. Psychiatric Quarterly, 32, 652-78.

Bell, D. 1982. Regret in decision making under uncertainty. Operations Research, 30, 961-981.

Binder, D. \& Iskandar, B. 2000. Modern neurosurgery for psychiatric disorders. Neurosurgery, 47, $9-21$.

British Medical Journal Editorial. 1965. Prefrontal leucotomy. British Medical Journal, 24 April 1965,1083-4.

Board of Control. 1947. Prefrontal Leucotomy in 1000 Cases. London: HMSO 1947.

Burckhardt, G. 1891. Ueber Rindenexcisionen, als Beitrag zur operativen therapie der Psychosen. Allgemeine Zeitschrift für Psychiatrie, 47, 463-548.

Canadian Medical Association Journal Editorial 1964. Standard lobotomy: the end of an era. Canadian Medical Association Journal, 91, 1228.

Cohen, B. 1996. Is expected utility theory normative for medical decision making? Medical Decision Making, 16, 1-16. 
Curran, D. \& Partridge, P. (1963). Psychological medicine. $5^{\text {th }}$ edition. Edinburgh: E \& S Livingstone Ltd.

Day, E. 2008. He was so bad they put an ice pick in his brain. The Observer Sunday 13 Jan available at http://www.guardian.co.uk/science/2008/jan/13/neuroscience.medicalscience

Deutsch, A. 1948. The shame of the states. New York: Harcourt, Brace..

Dully, H. \& Fleming, C. 2008. My lobotomy: A memoir. Random House

El-Hai, J. 2005. The lobotomist. Hoboken, New Jersey: John Wiley.

Elliott, C. 1999. A Philosophical Disease: Bioethics, Culture and Identity. London: Routledge.

Fleming, G. 1944. Prefrontal leucotomy. Journal of Mental Science, XC, 486-500.

Freeman, W. 1949. Transorbital lobotomy. American Journal of Psychiatry, 105, 734-740.

Freeman, W. 1953. Level of achievement after lobotomy. American Journal of Psychiatry, 110, 26976.

Freeman, W. \& Watts, J. 1937. Prefrontal lobotomy in the treatment of mental disorders. Southern Medical Journal, 30, 23-31.

Freeman, W. \& Watts, J. 1950. Psychosurgery. $2^{\text {nd }}$ edition. Oxford: Blackwell.

Freeman, W., Watts, J., Hunt, T. 1942. Psychosurgery. Springfield, Baltimore: Thomas.

Friedman, S., Moore, B., Ranger, C. \& Russman, C. 1951. A progress study of lobotomised and control patients. American Journal of Psychiatry, 108, 10-18.

Goldbeck-Wood, S. 1996. Norway compensates lobotomy victims. British Medical Journal, 313, 708.2

Greenblatt, M. \& Soloman, H. 1953. Frontal lobes and schizophrenia. New York: Springer.

Halter, A. \& Dean, G. 1971. Decisions under uncertainty. Cincinnati: South-Western Publishing Co.

Heath, R. (Ed.). 1954. Studies in schizophrenia. Cambridge, Massachusetts: Harvard University Press. 
Hunink, M. , Glasziou, P., Weinstein, M. 2001. Decision making in health and medicine. Cambridge: Cambridge University Press.

Johnson, J. 2009. A dark history: memories of lobotomy in the new era of psychosurgery. Medicine Studies, 1, 367-378.

Jones, K. 2000. Insulin coma therapy in schizophrenia. Journal of the Royal Society of Medicine, 93,147-9.

Kahneman, D. \& Tversky, A. 1979. Prospect theory: An analysis of decision under risk. Econometrics, 47, 263-292.

Kirsch I, Deacon BJ, Huedo-Medina TB, Scoboria A, Moore TJ, et al. 2008. Initial Severity and Antidepressant Benefits: A Meta-Analysis of Data Submitted to the Food and Drug Administration. PLoS Med 5(2): e45. doi:10.1371/journal.pmed.0050045

Kopeloff, N. \& Kirby, G. 1923. Focal infection and mental disease. American Journal of Psychiatry, $3,149-197$.

Loomes, G. \& Sugden, R. 1982. Regret theory: An alternative theory of rational choice under uncertainty. The Economic Journal, 92, 805-824.

Luce, R. \& Raiffa, H. 1967. Games and decisions. New York: John Wiley and Sons.

Maisel, A. 1946. Bedlam 1946. Life. 6 May 1946, pp102-118.

McKenzie, K. \& Kaczanowski, G. 1964. Prefrontal leukotomy: A five-year controlled study. The Canadian Medical Association Journal, 91, 1193-1196.

Mill, J.S. 1991. On liberty and other essays. Oxford: Oxford University Press.

Moniz, E. 1936. Essai d'un traitement chirurgical de certaines psychoses. Bulletin de l'Academie de Médicine, 115, 385-392. Translated as “Attempt at surgical treatment of certain psychoses”. Journal of Neurosurgery 1964. 21, 1110-4. 
Moniz, E. 1937. Prefrontal leucotomy in the treatment of mental disorders. American Journal of Psychiatry, 93, 1379-1385.

O’Callaghan, M. \& Carroll, D. 1982. Psychosurgery: A scientific analysis. Lancaster: MTP Press Limited.

Oltman, J., Brody, B., Friedman, S. \& Green, W. 1949. Frontal lobotomy: Clinical experience with 107 cases in a state hospital. American Journal of Psychiatry, 105, 742-739.

Partridge, M. 1950. Pre-frontal leucotomy: A survey of 300 cases personally followed over 1 1/2 - 3 years. Oxford: Blackwell.

Penrose, L \& Marr, W. 1943. Results of shock therapy evaluated by estimating chances of patients remaining in hospital without such treatment. British Journal of Psychiatry, 89, 374-380.

Polatin, P. \& Philtine, E. 1951. How psychiatry helps. Kingswood, Surrey: The World's Work. Pressman, J. 1998. Last resort: Psychosurgery and the limits of medicine. Cambridge: Cambridge University Press.

Rao, G. 2007. Rational medical decision making. New York: McGraw Hill.

Resnik, D. 2004. The precautionary principle and medical decision making. Journal of Medicine and Philosophy, 29: 281-299.

Robin, A. 1958. A controlled study of the effects of leucotomy. Journal of Neurology, Neurosurgery and Psychiatry, 21, 262-269.

Robin, A. \& Macdonald, D. 1975. Lessons of leucotomy. London: Henry Kimpton Publishers.

Rupp, C \& Fletcher, E. 1940. Five to ten year follow-up study of 641 schizophrenic cases. American Journal of Psychiatry, 96, 877-888.

Sargant, W. 1967. The unquiet mind. London: Heinemann.

Sargant, W. \& Slater, E. 1964. Physical methods of treatment in psychiatry. $4^{\text {th }}$ edition. Edinburgh: E \& S Livingstone.

Savage, L. 1954. The foundations of statistics. New York: Wiley. 
Schwartz, A. \& Bergus, G. 2008. Medical decision making. Cambridge: Cambridge University Press. Seabrook, W. 1935. Asylum. London: George G. Harrap and Co Ltd.

Semelaigne, R. 1895. Sur la chirurgie cérébrale dans les aliénations mentales. Annales MédicoPsychologiques, 1, 394-420.

Silbermann, M. \& Ransohoff, J. 1954. Medico-legal problems in psychosurgery. American Journal of Psychiatry, 110, 801-808.

Smith, R. 1996. Is regret theory an alternative basis for estimating the value of healthcare interventions? Health Policy, 37, 105-115.

Sox, H., Blatt, M., Higgins, M. \& Marton, K. 1988. Medical decision making. Boston: Butterworths. Sutherland, J. 2004. Should they de-Nobel Moniz? The Guardian, Monday August 2 2004, http://www.guardian.co.uk/g2/story/0,1274065,00.html

Tymstra, T. 1989. The imperative character of medical technology and the meaning of "anticipated decision regret”. International Journal of Technology Assessment in Health Care, 5, 207-213.

Valenstein, E. 1976. The practice of psychosurgery: A survey of the literature (1971-1976). Report to the U.S. Commission for the Protection of Human Subjects in Biomedical and Behavioral Research, August 1, 1976, pp. 1-183. U.S. Department of Health, Education, and Welfare. DHEW Pub. No. (OS)77-0002.

Valenstein, E. 1986. Great and desperate cures. New York: Basic Books.

White, W. 2003. A History of Contempt: Countertransference and the Dangers of Service Integration. Counselor: The Magazine for Addiction Professionals, 4, 20.

Ziegler, L. 1943. Bilateral prefrontal lobotomy. American Journal of Psychiatry, 100, 178-179. 


\section{Endnotes}

${ }^{1}$ For discussion of the information given to patients and families see Silbermann and Ransohoff (1954). Popular texts aimed at lay people, including families and patients, repeated the statistics found in medical papers and textbooks - that with lobotomy $1 / 3$ recovered, $1 / 3$ improved, and $1 / 3$ failed to improve, and that the mortality rate was $3 \%$ (Polatin $\&$ Philtine (1951)).

${ }^{2}$ In 1890 Gottlieb Burckhardt, director of the Swiss asylum of Préfargier, operated on six patients and reported some success. Burckhardt was condemned and the operations discontinued. (Burckhardt, 1891) for contemporary condemnation see Semelaigne (1895). For a review of later and more sophisticated psychosurgical operations see Valenstein (1976) for a review of practices in the 1970s, and Binder \&Iskander (2000) for a review of later practices. ${ }^{3}$ Although some early controlled studies had already been performed, eg Kopeloff \& Kirby (1923) performed a trial of Henry Cotton's surgical treatment for mental disorders. The need for controlled trials of psychosurgery was felt by at least some; in his memoir, William Sargant (1967) says that a controlled study of transorbital lobotomy was planned at Tuskegee VA Hospital, but that the planned operations were stopped by the VA administration.

${ }^{4}$ White (2003) claims Seabrook was admitted to Bloomingdale but provides no references to support this.

${ }^{5}$ When the probabilities are unknown then different methods are required, such as maximin, or some version of the precautionary principle (Resnik, 2004)

${ }^{6}$ Some patients had more than one lobotomy, as if an operation was unsuccessful a surgeon might decide to re-operate and sever more brain tissue.

${ }^{7}$ I am grateful to Jonathan Wolff for pointing out the importance of the variance of outcomes to me.

${ }^{8}$ A related approach is Kahneman and Tversky (1979) "prospect theory" 
${ }^{9}$ If post-lobotomy "recoveries" are judged only $15 \%$ as good on average as spontaneous recoveries then the expected utility of the two options are equal.

${ }^{10}$ For discussion see Valenstein (1976), pp.63-64.

${ }^{11}$ Though some, for example, Sargant and Slater (1964) continued to claim that psychosurgery played a useful role in psychiatry.

${ }^{12}$ El Hai (2005) describes how Walter Freeman gradually shifted from thinking of lobotomy as the "last resort" to advocating its use comparatively early, before “deterioration” had set in. In My Lobotomy: A Memoir (2008) Howard Dully relates how he came to be lobotomised at aged 12 though his behaviour was far from unusual (he was naughty and anxious) .

${ }^{13}$ H. Ford and G. Jameson (1955) Chlorpromazine in conjunction with other psychiatric therapies: A clinical appraisal. Diseases of the Nervous System, 16, 179-85. Quoted in Pressman (1998), p. 440.

${ }^{14}$ Furthermore, bureaucratic constraints may mean that those who are given one therapy are then excluded from further clinical trials.

${ }^{15}$ For example, in the U.K. data is now collected on Patient Reported Outcome Measures (PROMs), and this data might be of some use if, for example, I am considering whether to undergo a hip operation . 